METALLURGY AND FOUNDRY ENGINEERING - Vol. 38, 2012, №. 2

http://dx.doi.org/10.7494/mafe.2012.38.2.117

Maciej Rumiński*

\title{
THE INFLUENCE OF CONSTRUCTION METHOD SELECTION ON THE CHARACTER OF HARDNESS CURVE OF AISI 316Cu ACID RESISTANT STEEL
}

\section{INTRODUCTION}

Austenitic stainless steels are the most important group of corrosion-resistant metallic materials finding widespread industrial application [1]. They show high corrosion resistance in various corrosive environments, resulting in extensive use in architectural, structural, as well as food and surgical applications. In the annealed state, these steels show quite a low strength level, considering especially the yield strength. Significant strengthening can be achieved by cold plastic deformation. The strain-hardening character of each austenitic steel is a result of the interdependence between chemical composition, phase composition, texture evolution and microstructure. Thus, the variations of mechanical properties of these steels, as a result of plastic deformation, should be always discussed in wide aspect of combined effect of different influencing factors [2-5]. Emphasis should be also put on the problem of strain redundancy and the effect of its level on true strain distribution, which is of significant importance especially in case of heavy multi-stage deformation.

The knowledge of mechanical behaviour of the material during deformation process is of substantial importance, as it allows the proper design of the process technology in order to obtain the final product having required properties. Generally, the mechanical properties of a material are being reported as average values, with no consideration given to their distribution on the cross-section of a product. This may lead to incorrect or at least incomplete evaluation of material's effort as a result of loading.

Therefore, it is useful to have a suitable technique available, which allows to predict the distribution of mechanical properties in deformed products. The method of strain field analysis based on hardness measurements can be applied for this purpose [6-10]. In order to

* Ph.D.: AGH University of Science and Technology, Faculty of Metals Engineering and Industrial Computer Science, Krakow, Poland; e-mail: ruminski@agh.edu.pl 
make use of this method, first the material's characteristic in a form of hardness curve has to be determined. Hardness curve is a relationship between hardness and effective strain and can be obtained experimentally with application of several methods. This paper presents the construction of hardness curve based on three different experimental techniques, performed for AISI 316Cu acid resistant steel.

\section{EXPERIMENTAL PROCEDURE}

\subsection{Material description}

The material selected to the investigations was AISI 316Cu austenitic acid resistant steel (material no. 1.4578: X3CrNiCuMo17-11-3-2 according to EN 10088). The chemical composition of the steel being tested is given in Table 1 . The material was supplied in a form of drawn wire of $8 \mathrm{~mm}$ diameter, in the solution annealed condition, showing tensile strength at the level of $500 \mathrm{MPa}$ and $89 \%$ of elongation.

Table 1. Chemical composition of AISI $316 \mathrm{Cu}$ steel used in the investigations [\%]

\begin{tabular}{|c|c|c|c|c|c|c|c|c||}
\hline $\mathrm{C}$ & $\mathrm{Mn}$ & $\mathrm{Si}$ & $\mathrm{P}$ & $\mathrm{S}$ & $\mathrm{Cr}$ & $\mathrm{Ni}$ & $\mathrm{Mo}$ & $\mathrm{Cu}$ \\
\hline 0.016 & 0.78 & 0.45 & 0.022 & 0.002 & 16.7 & 10.01 & 2.19 & 3.21 \\
\hline
\end{tabular}

AISI $316 \mathrm{Cu}$ is a chromium-nickel-molybdenum austenitic steel with low carbon content and copper addition, showing very good corrosion resistance, average mechanical properties, as well as good forgeability, weldability and machinability. It is suited to a very high degree of cold deformation, e.g. in cold heading or drawing processes. Typical applications of AISI $316 \mathrm{Cu}$ steel grade include chemical industry, food and beverage industry, decorative items and kitchen utensils, electronic equipment, ship building, as well as screw and fastening industry.

\subsection{Construction of hardness curve}

The methods selected to the experimental determination of hardness curve of the steel being investigated are based on three different deformation modes, including uniaxial tension, frictionless compression and wire drawing process. The most important problem is to achieve the maximum attainable uniform deformation, thus defining the range within which the hardness curve can be constructed. These three methods differ considerably as concerns the possible range of uniform deformation, which is most limited in uniaxial tension. The wire drawing process makes it possible to achieve the highest level of uniform strain, being however limited to the wire axis. These differences make the selection of construction methods reasonable, from a comparative point of view. Different states of stress and strain can be compared considering their influence on deformation capability of a material.

\section{Method based on tensile test}

The method based on tensile testing required the preparation of a series of specimens by cutting a set of equal lengths of wire (Fig. 1a). One of them was used to establish the upper 
limit of uniform elongation and the corresponding load. Twenty one specimens were subjected to uniaxial tension, applying stepwise increase of load, resulting in different value of uniform elongation obtained for each specimen. Tensile testing was realized using Instron 1196 testing machine, with application of Hottinger Baldwin Messtechnik MGCplus measuring apparatus (Fig. 1b,c). After the test, a short section was cut out from each specimen, in order to perform hardness measurements. The preparation of metallographic specimens on wire cross sections is described in point Hardness measurements.

a)

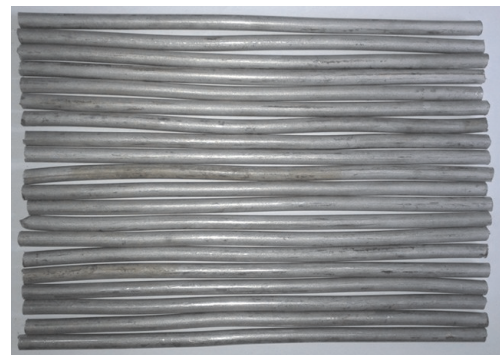

b)

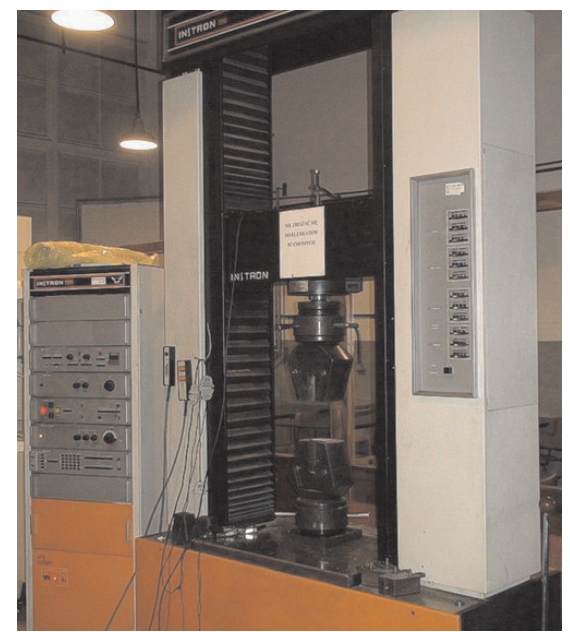

c)

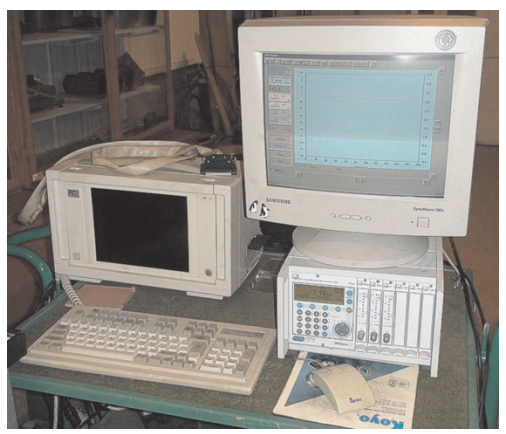

Fig. 1. Tensile specimens (a) and Instron 1196 testing machine (b) with measuring apparatus (c) 
The effective strain value for each specimen was calculated using the following formula:

$$
\varepsilon_{i}=2 \ln \frac{d_{0}}{d}
$$

where $d_{0}$ is the initial wire diameter $\left(d_{0}=8 \mathrm{~mm}\right)$ and $d$ is the diameter of unloaded specimen after tensile testing. The results of calculations as well as the loads and geometry of specimens are given in Table 2 .

Table 2. Tensile testing parameters and calculated effective strain for AISI $316 \mathrm{Cu}$ steel specimens subjected to uniaxial tension

\begin{tabular}{|c|c|c|c|}
\hline \multirow{2}{*}{$\begin{array}{l}\text { Specimen } \\
\text { number }\end{array}$} & Load & $\begin{array}{c}\text { Specimen } \\
\text { diameter }\end{array}$ & Effective strain \\
\hline & {$[\mathrm{kN}]$} & {$[\mathrm{mm}]$} & - \\
\hline 1 & 15.0 & 7.85 & 0.038 \\
\hline 2 & 17.0 & 7.82 & 0.046 \\
\hline 3 & 17.5 & 7.81 & 0.048 \\
\hline 4 & 18.0 & 7.78 & 0.056 \\
\hline 5 & 18.5 & 7.75 & 0.063 \\
\hline 6 & 19.0 & 7.73 & 0.069 \\
\hline 7 & 19.5 & 7.70 & 0.076 \\
\hline 8 & 20.0 & 7.66 & 0.087 \\
\hline 9 & 20.5 & 7.65 & 0.089 \\
\hline 10 & 21.0 & 7.62 & 0.097 \\
\hline 11 & 21.5 & 7.58 & 0.108 \\
\hline 12 & 22.0 & 7.56 & 0.113 \\
\hline 13 & 22.5 & 7.53 & 0.121 \\
\hline 14 & 23.0 & 7.50 & 0.129 \\
\hline 15 & 23.5 & 7.47 & 0.137 \\
\hline 16 & 24.0 & 7.45 & 0.142 \\
\hline 17 & 24.5 & 7.42 & 0.151 \\
\hline 18 & 25.0 & 7.38 & 0.161 \\
\hline 19 & 25.5 & 7.31 & 0.180 \\
\hline 20 & 26.0 & 7.27 & 0.191 \\
\hline 21 & 26.5 & 7.18 & 0.216 \\
\hline
\end{tabular}




\section{Method based on frictionless compression test}

The method based on compression test also required the preparation of a series of specimens. In order to minimize friction at the tool/workpiece interface, Rastegaev specimens were prepared (Fig. 2a). The flat recesses at the ends of each specimen were filled with lubricant (paraffin). This made it possible to prevent barrelling during compression, thus producing favourable conditions for uniform deformation. One specimen was used to establish the upper limit of uniform deformation and the corresponding load. Eighteen Rastegaev specimens were subjected to compression, applying stepwise increase of load, resulting in different value of uniform deformation obtained for each specimen. Complete set of specimens collected after compression is presented in Figure 2b. After replacing holding jaws with compression plates, Instron 1196 testing machine was used in the experiment, with application of the same measuring apparatus as in case of uniaxial tension. The preparation of metallographic specimens for hardness measurements is described in point Hardness measurements.

b)
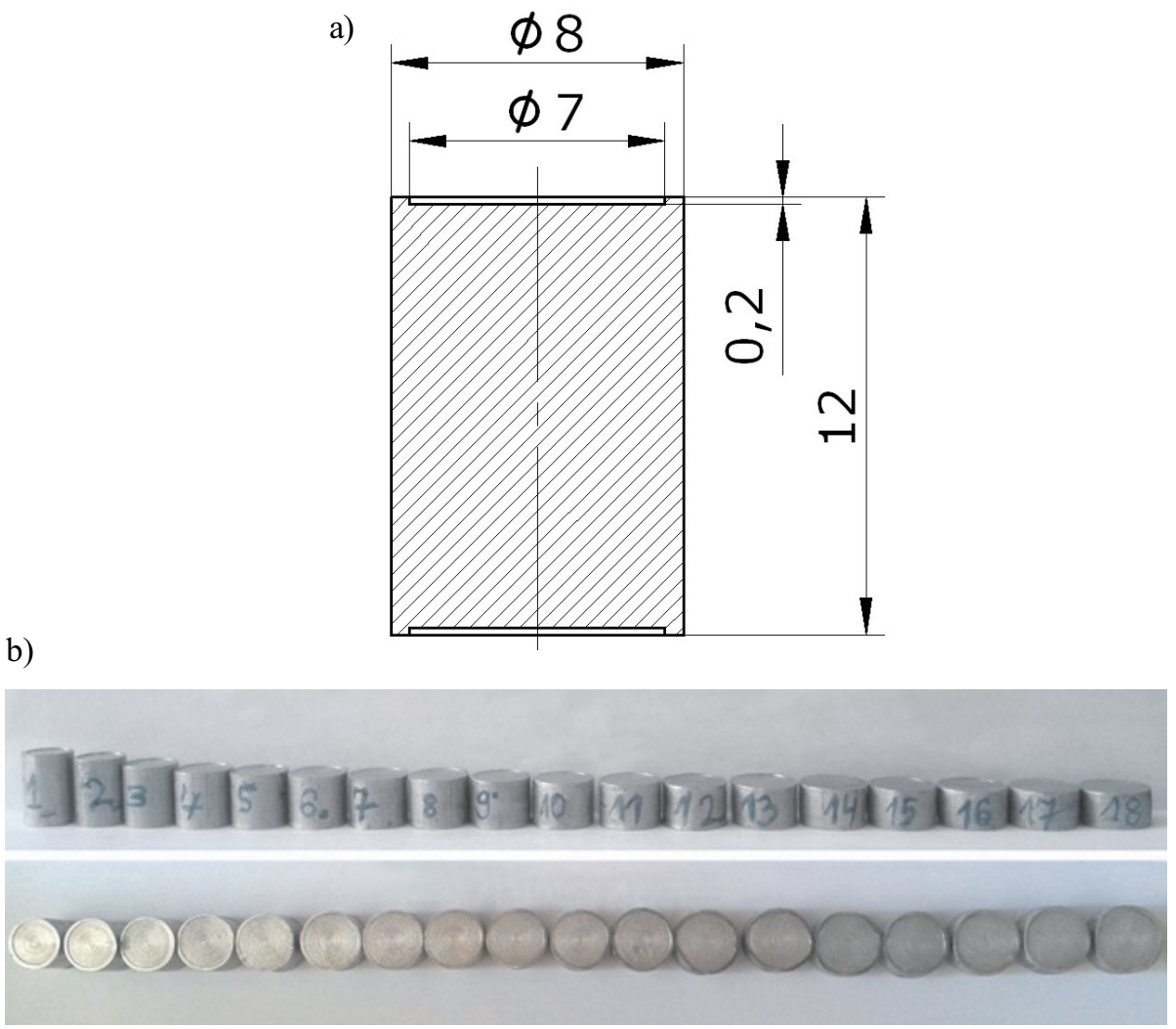

Fig. 2. Geometry of Rastegaev specimens used in compression test (a) and the whole set of specimens after compression (b) 
The effective strain value for each specimen was calculated using the following formula:

$$
\varepsilon_{i}=\ln \frac{h_{0}}{h}
$$

where $h_{0}$ is the initial height of a specimen $\left(h_{0}=12 \mathrm{~mm}\right)$ and $h$ is a height of unloaded specimen after compression. The results of calculations as well as the loads and geometry of specimens are given in Table 3 .

Table 3. Compression test parameters and calculated effective strain for AISI $316 \mathrm{Cu}$ steel specimens subjected to frictionless compression

\begin{tabular}{|c|c|c|c|c|}
\hline Specimen & Load & $\begin{array}{c}\text { Specimen } \\
\text { diameter }\end{array}$ & Specimen height & Effective strain \\
\hline & {$[\mathrm{kN}]$} & {$[\mathrm{mm}]$} & {$[\mathrm{mm}]$} & - \\
\hline 1 & 10 & 8.07 & 11.95 & 0.004 \\
\hline 2 & 20 & 8.40 & 11.15 & 0.073 \\
\hline 3 & 30 & 8.77 & 10.10 & 0.172 \\
\hline 4 & 40 & 8.99 & 9.28 & 0.257 \\
\hline 5 & 45 & 9.24 & 8.91 & 0.298 \\
\hline 6 & 50 & 9.36 & 8.54 & 0.340 \\
\hline 7 & 55 & 9.59 & 8.16 & 0.386 \\
\hline 8 & 60 & 9.75 & 8.07 & 0.397 \\
\hline 9 & 65 & 9.84 & 7.81 & 0.430 \\
\hline 10 & 70 & 10.06 & 7.49 & 0.471 \\
\hline 11 & 75 & 10.34 & 7.23 & 0.507 \\
\hline 12 & 80 & 10.51 & 6.95 & 0.546 \\
\hline 13 & 85 & 10.64 & 6.82 & 0.565 \\
\hline 14 & 90 & 11.04 & 6.62 & 0.595 \\
\hline 15 & 95 & 11.12 & 6.50 & 0.613 \\
\hline 16 & 100 & 11.27 & 6.30 & 0.644 \\
\hline 17 & 105 & 11.39 & 6.07 & 0.682 \\
\hline 18 & 110 & 11.41 & 5.91 & 0.708 \\
\hline
\end{tabular}

\section{Method based on drawing process}

The method based on multi-pass wire drawing process allowed to extend the range of uniform deformation significantly. The state of strain occurring in axisymmetrical drawing is 
strongly affected by the presence of redundant strains, which influence the distribution of effective strain on the wire cross section. However, considering the character of material flow during drawing, it is obvious that wire axis is free from strain redundancy, i.e. the deformation at the axis is uniform and can be easily determined.

The chain drawbench was used in the experiment and the wire was drawn in seventeen consecutive passes to the final diameter of $2.63 \mathrm{~mm}$. Sintered carbide dies with $12^{\circ}$ die angle were applied. Sodium soap powder was used as a lubricant and the drawing velocity of $0.1 \mathrm{~m} / \mathrm{s}$ was applied in the experiment. After each pass, a short section was cut out from wire, in order to perform hardness measurements. The preparation of metallographic specimens on wire cross sections is described in point Hardness measurements.

The effective strain value for each specimen was calculated using the formula (1), where $d_{0}$ is the initial wire diameter $\left(d_{0}=8 \mathrm{~mm}\right)$ and $d$ is the diameter of wire after the consecutive pass. The results of calculations are collected in Table 4.

Table 4. Deformation parameters and calculated effective strain for AISI $316 \mathrm{Cu}$ steel wire subjected to multi-pass drawing

\begin{tabular}{|c|c|c|c|c|}
\hline \multirow{2}{*}{$\begin{array}{l}\text { Number } \\
\text { of pass }\end{array}$} & $\begin{array}{c}\text { Wire } \\
\text { diameter }\end{array}$ & $\begin{array}{c}\text { Unit } \\
\text { reduction }\end{array}$ & $\begin{array}{c}\text { Total } \\
\text { reduction }\end{array}$ & Effective strain \\
\hline & {$[\mathrm{mm}]$} & {$[\%]$} & {$[\%]$} & - \\
\hline 1 & 7.74 & 6.39 & 6.39 & 0.066 \\
\hline 2 & 7.34 & 10.07 & 15.82 & 0.172 \\
\hline 3 & 6.94 & 10.60 & 24.74 & 0.284 \\
\hline 4 & 6.44 & 13.89 & 35.20 & 0.434 \\
\hline 5 & 5.94 & 14.93 & 44.87 & 0.595 \\
\hline 6 & 5.75 & 6.29 & 48.34 & 0.660 \\
\hline 7 & 5.18 & 18.84 & 58.07 & 0.869 \\
\hline 8 & 4.94 & 9.05 & 61.87 & 0.964 \\
\hline 9 & 4.82 & 4.80 & 63.70 & 1.013 \\
\hline 10 & 4.53 & 11.67 & 67.94 & 1.137 \\
\hline 11 & 4.17 & 15.26 & 72.83 & 1.303 \\
\hline 12 & 3.85 & 14.76 & 76.84 & 1.463 \\
\hline 13 & 3.73 & 6.14 & 78.26 & 1.526 \\
\hline 14 & 3.34 & 19.82 & 82.57 & 1.747 \\
\hline 15 & 3.07 & 15.51 & 85.27 & 1.916 \\
\hline 16 & 2.97 & 6.41 & 86.22 & 1.982 \\
\hline 17 & 2.63 & 21.59 & 89.19 & 2.225 \\
\hline
\end{tabular}




\section{Hardness measurements}

Prior to hardness measurements, the complete set of specimens taken from tension, compression and drawing methods had to be suitably prepared. Struers Discotom-5 cut-off machine (Fig. 3a) was used to level both ends of each specimen, making the surfaces parallel to each other and perpendicular to the axis. Then all specimens were assembled in several groups and put into cylindrical moulds (Fig. 3b). Each mould was filled with special cold-setting resin in order to mount the test specimens, so that they could be subjected to surface treatment by machining. Grinding and polishing was realized with application of Struers LaboPol-5 machine equipped with LaboForce-3 specimen mover allowing semi-automatic preparation of metallographic specimens (Fig. 4a). Struers MD-System grinding wheels and $\mathrm{SiC}$ foils as well as MD-Chem polishing cloth with OP-AA suspension $\left(\mathrm{Al}_{2} \mathrm{O}_{3}\right)$ were applied. As a result, a set of metallographic specimens was obtained to be finally subjected to hardness measurements (Fig. 4b).

a)

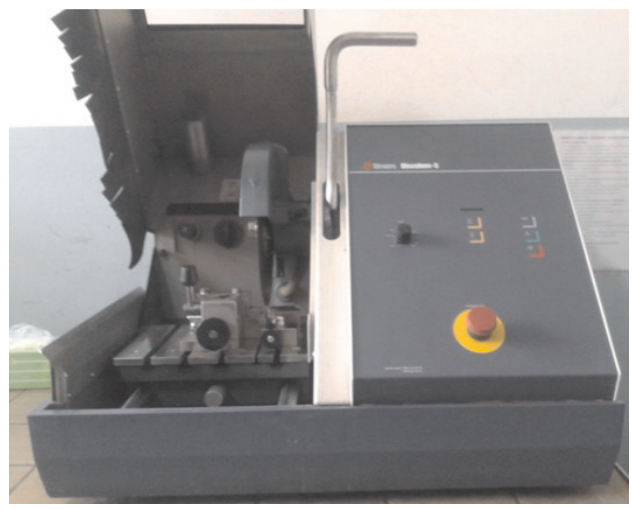

b)

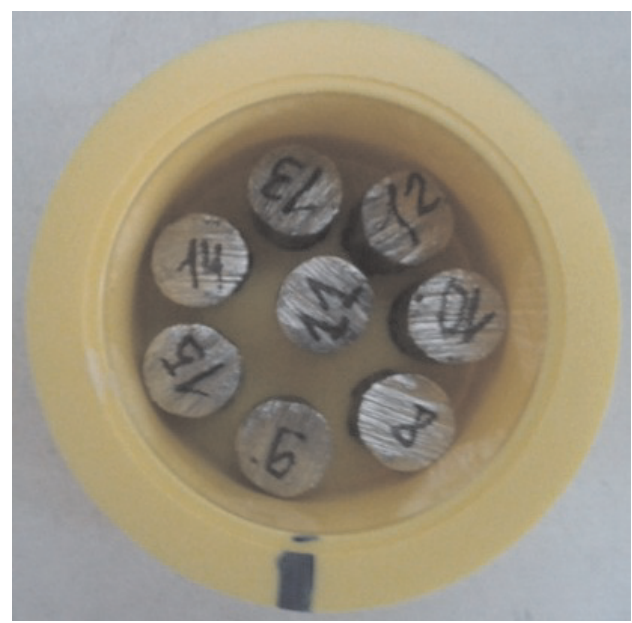

Fig. 3. Struers Discotom-5 cut-off machine (a) and set of specimens prepared for mounting (b) 
a)

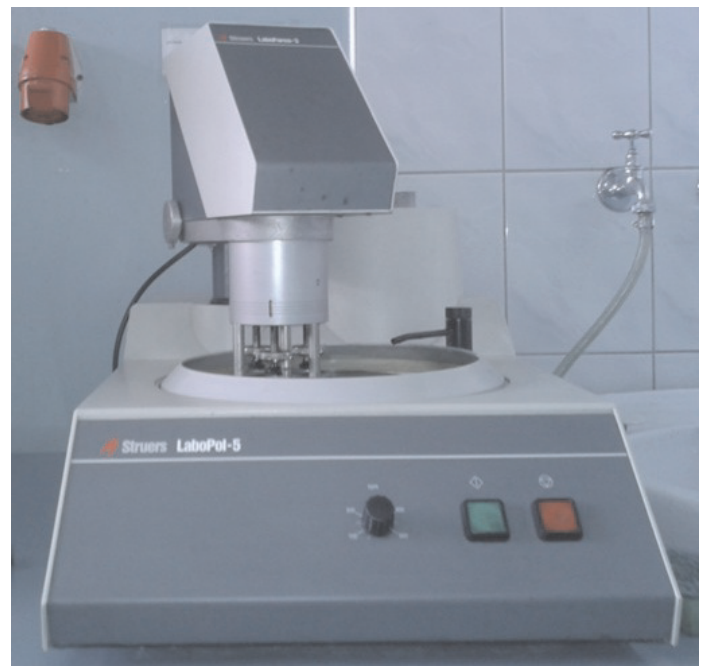

b)

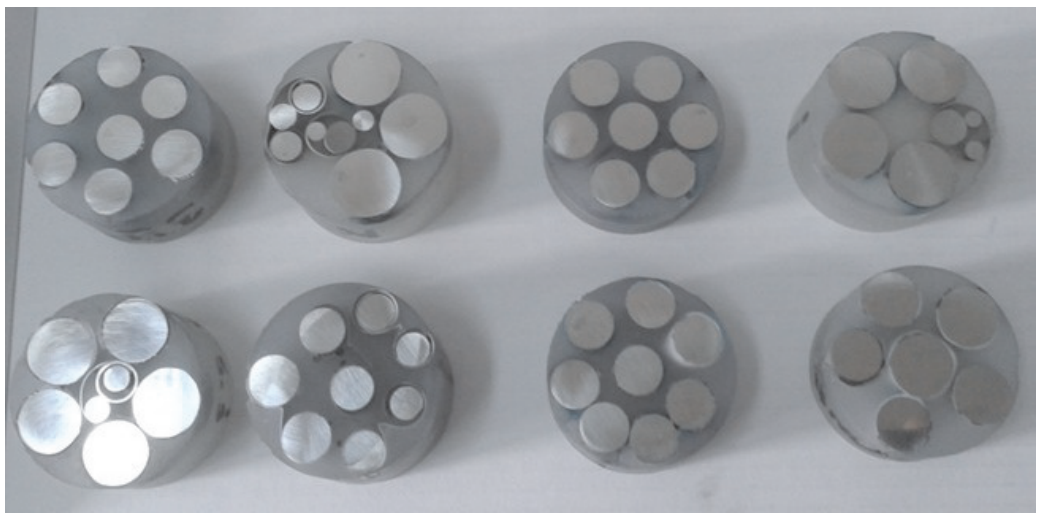

Fig. 4. Struers LaboPol-5 grinding and polishing machine with LaboForce-3 specimen mover (a) and metallographic specimens after final polishing (b)

Hardness measurements were performed using Zwick 3212002 hardness tester, applying Vickers indenter under $2 \mathrm{~kg}$ load (Fig. 5). The hardness tester was coupled with a PC computer and dedicated Zwick software was used for automatic registration of results. In case of specimens taken from tension and compression methods, a few measurements were made on the cross section of each specimen, producing the average result calculated from them. Each specimen taken from wire drawing method was subjected to only one hardness measurement, performed at the axis of wire. The hardness of undeformed material was also measured and it amounted to $132 \mathrm{HV} 2$. Table 5 presents the results of all measurements obtained for specimens subjected to uniaxial tension, frictionless compression and drawing, as well as the ranges of standard deviation $(\sigma)$ obtained for HV2 measurements in tension and compression methods. 


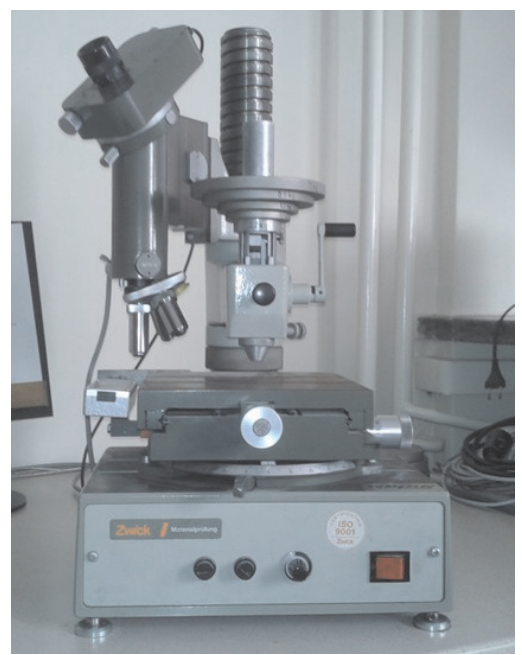

Fig. 5. Zwick 3212002 hardness tester used for HV measurements

Table 5. Results of hardness measurements of specimens subjected to different deformation modes

\begin{tabular}{|c|c|c|c|c|c|}
\hline \multicolumn{2}{|l|}{ Tension } & \multicolumn{2}{|c|}{ Compression } & \multicolumn{2}{|c|}{ Wire drawing } \\
\hline Specimen number & HV2 & Specimen number & HV2 & Specimen number & HV2 \\
\hline 1 & 153.8 & 1 & 133.7 & 1 & 168.0 \\
\hline 2 & 166.4 & 2 & 166.2 & 2 & 209.8 \\
\hline 3 & 177.3 & 3 & 199.4 & 3 & 221.6 \\
\hline 4 & 178.3 & 4 & 222.8 & 4 & 268.0 \\
\hline 5 & 179.8 & 5 & 243.7 & 5 & 296.4 \\
\hline 6 & 179.8 & 6 & 250.8 & 6 & 313.0 \\
\hline 7 & 186.8 & 7 & 260.8 & 7 & 327.2 \\
\hline 8 & 183.5 & 8 & 271.7 & 8 & 324.1 \\
\hline 9 & 197.1 & 9 & 272.3 & 9 & 331.9 \\
\hline 10 & 196.1 & 10 & 282.7 & 10 & 335.1 \\
\hline 11 & 205.5 & 11 & 295.1 & 11 & 337.8 \\
\hline 12 & 202.2 & 12 & 297.4 & 12 & 348.7 \\
\hline 13 & 207.9 & 13 & 301.8 & 13 & 355.3 \\
\hline 14 & 208.3 & 14 & 298.1 & 14 & 358.3 \\
\hline 15 & 208.9 & 15 & 307.5 & 15 & 362.8 \\
\hline 16 & 200.9 & 16 & 310.1 & 16 & 364.6 \\
\hline 17 & 209.9 & 17 & 317.6 & 17 & 370.2 \\
\hline 18 & 217.1 & 18 & 321.9 & & \\
\hline 19 & 218.8 & \multirow{3}{*}{\multicolumn{4}{|c|}{$\begin{array}{l}\text { Standard deviation range for HV2 measurements: } \\
\text { a) tension: } \quad \sigma=0.42-2.97 \\
\text { b) compression: } \sigma=0.96-4.65\end{array}$}} \\
\hline 20 & 216.8 & & & & \\
\hline 21 & 222.3 & & & & \\
\hline
\end{tabular}




\section{RESULTS AND DISCUSSION}

The construction of hardness curve of AISI $316 \mathrm{Cu}$ steel was based on the calculations of effective strain performed for each specimen, according to formulae (1) or (2), and the measurements of HV2 hardness made on cross sections of specimens. The source data collected in Tables 2-5 allowed to present the relationships graphically. The effect is shown in Figures 6 and $7 \mathrm{a}$.

a)

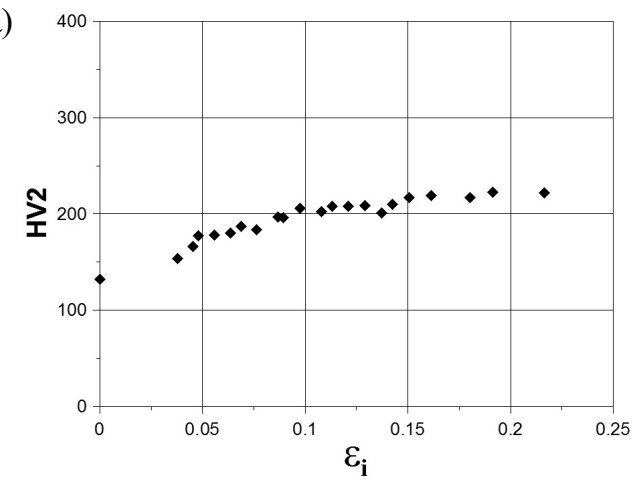

b)

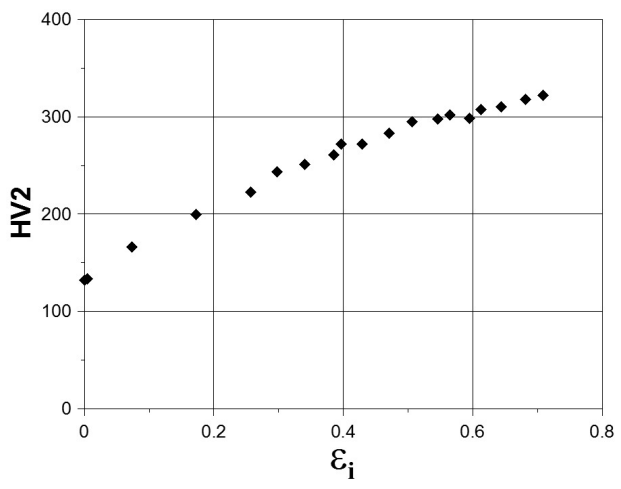

c)

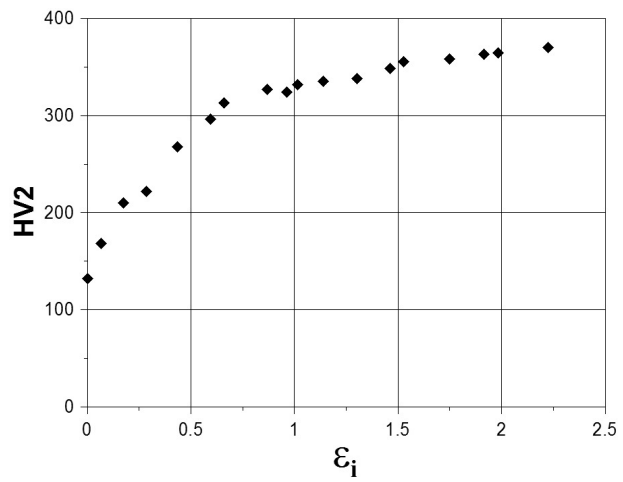

Fig. 6. Hardness as a function of effective strain in uniaxial tension (a), frictionless compression (b) and wire drawing (c) 
a)
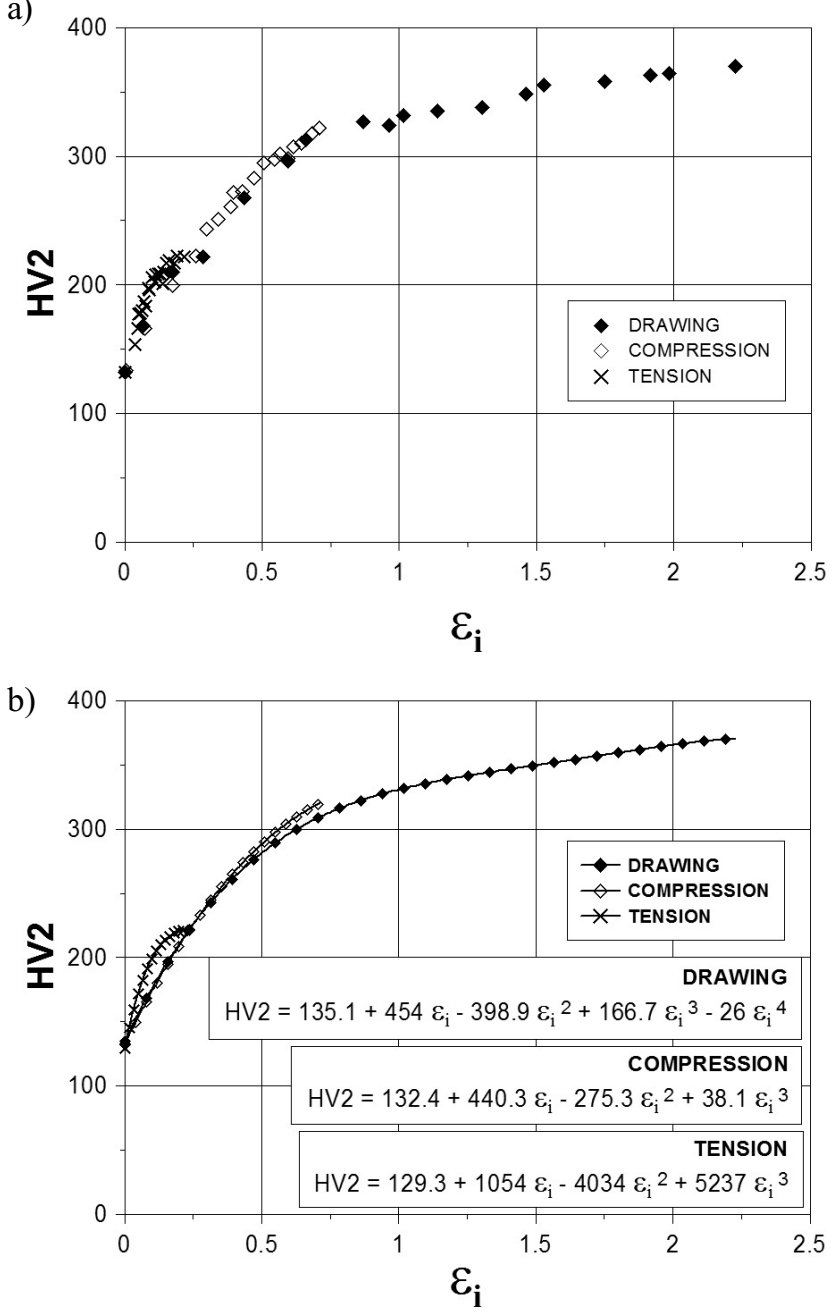

Fig. 7. Comparison of hardness - effective strain relationships for different deformation modes (a) and hardness curves obtained as a result of approximation by polynomial (b)

The results of hardness measurements were approximated using polynomial function. Hardness curves obtained as a result of approximation are presented in Figure $7 \mathrm{~b}$, together with the equations describing the relationships. In order to generalize the material's characteristic basing on the three methods applied, all the results were put together and one resultant hardness curve was obtained by approximation.

The curve is shown in Figure 8 and described by the following equation:

$$
\mathrm{HV} 2=149.6+436.7 \varepsilon_{\mathrm{i}}-400.9 \varepsilon_{\mathrm{i}}^{2}+174.7 \varepsilon_{\mathrm{i}}^{3}-28.2 \varepsilon_{\mathrm{i}}^{4}
$$




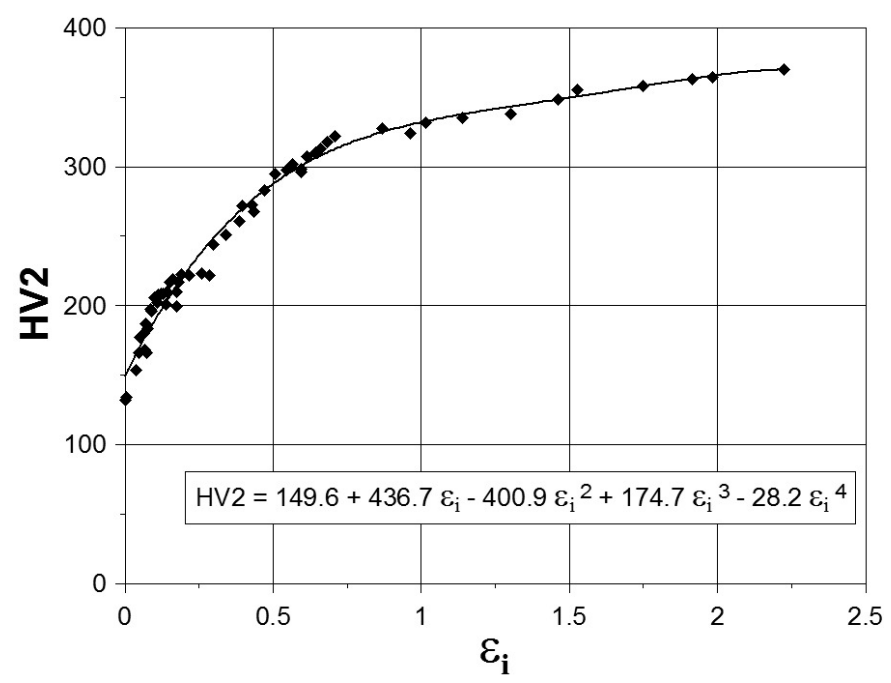

Fig. 8. Generalized hardness curve of AISI 316Cu steel obtained by means of integration of the whole set of results

The results put together in Fig. 7a as well as the curves presented in Figure $7 \mathrm{~b}$ allow to observe the differences in uniform deformation range, achieved in uniaxial tension, frictionless compression and wire drawing. The tensile stress conditions generate quite a narrow range of uniform deformation, with a maximum level of effective strain at about 0.22 (Fig. 6a). Much higher strain values were achieved in compression of Rastegaev specimens, amounting up to about 0.71 (Fig. 6b). The highest level of uniform strain (occurring at the wire axis) was obtained in wire drawing, with a maximum of $\varepsilon_{\mathrm{i}}=2.225$ (Fig. 6c). Good coincidence was observed between the results of compression and drawing methods, while the hardness curve obtained from uniaxial tension shows some discrepancy when compared to them. In case of tension, the same value of effective strain results in higher hardness than that of compressed or drawn material. This may result from the concentration of a large number of data in a narrow range of relatively low strains, thus increasing the accuracy in that region, while compression and drawing techniques generated only two measurement points each within the corresponding range. The reason for that discrepancy can also be the difference in material's plasticity, as influenced by the state of stress. Higher contribution of compressive stresses in a mean stress causes the increase of plasticity. In case of uniaxial tension, only one tensile stress is active, thus making the steel not susceptible to heavy plastic deformation. This may lead to more intensive strain hardening and, in consequence, higher hardness of a material.

However, the general coincidence of the whole set of results can be observed (Fig. 7a), making it possible to construct one generalized hardness curve of AISI $316 \mathrm{Cu}$ steel, by including all the data obtained from experiments in one approximation (Fig. 8). 


\section{CONCLUSIONS}

On the basis of the realized research work and the analysis of obtained results, the following conclusions and observations can be formulated:

- Mechanical properties of the steel being tested allowed to determine the material's characteristic with application of three different methods, representing three different states of stress.

- The methods of construction of hardness curve applied in the experiment differ considerably from each other, when comparing the ranges of achievable uniform deformation.

- The obtained relationships show good coincidence and can be complementary to each other. This allowed to construct one resultant hardness curve of AISI $316 \mathrm{Cu}$ steel.

- The results obtained from tension show a slight discrepancy when compared to two other methods. This may result from higher measuring accuracy in the range of small deformations, as well as from the influence of state of stress on material's plasticity.

- In the range of large deformations special emphasis should be put on the accuracy of measurements and calculations, considering the flattening of hardness curve.

\section{Acknowledgements}

Financial support of the Ministry of Science and Higher Education is gratefully acknowledged (AGH UST statutory research project no. 11.11.110.008).

\section{REFERENCES}

[1] Lamb S. (ed.): CASTI Handbook of stainless steels and nickel alloys, $2^{\text {nd }}$ edition, CASTI Publishing Inc., Canada, 2002

[2] Euksza J., Rumiński M., Ratuszek W., Blicharski M.: Texture evolution and variations of a-phase volume fraction in cold-rolled AISI 301 steel strip, Journal of Materials Processing Technology, 177 (2006), $\quad 555-560$

[3] Rumiński M., Euksza J.: Mechanical and structural behaviour of austenitic steels under heavy plastic deformation, Steel Research International, special edition: Proc. $14^{\text {th }}$ International Conference METAL FORMING 2012, Kraków, 2012, 943-946

[4] Euksza J., Rumiński M., Ratuszek W., Blicharski M.: Badania mechanizmu zmian plastyczności w stali AISI 302 ciągnionej z bardzo dużymi odkształceniami, Hutnik - Wiadomości Hutnicze, 74 (2007) 1$2, \quad 53-58$

[5] Ratuszek W., Kowalska J., Bunsch A., Rumiński M., Zielińska-Lipiec A.: Development of deformation texture of austenitic steel wires, Arch. of Met. and Materials, 53 (2008) 1, 167-174

[6] Osakada K., Niimi Y.: A study on radial flow field for extrusion through conical dies, International Journal of Mechanical Sciences, 17 (1975) 4, 241-254

[7] Wright R.N.: Applications of microhardness measurement to wire products analysis, Wire Journal, January 1981, 86-89 
[8] Cetlin P.R.: Redundant deformation factor evaluation through the hardness profile method in round section bar drawing, Journal of Eng. Materials and Technology, 106 (1984) 2, 147-151

[9] Łuksza J., Rumiński M.: Zastosowanie pomiarów twardości do analizy procesu ciągnienia, Hutnik Wiadomości Hutnicze, 60 (1993) 5, 164-170

[10] Rumiński M.: Zastosowanie pomiarów twardości do oceny lokalnych własności mechanicznych materiałów odkształconych plastycznie, Hutnik - Wiadomości Hutnicze, 60 (1993) 7, 220-226

Received

October 2012 